\title{
Pediatrics Standardized Concentration of Central Nervous System Intravenous Infusion Medications: A New Initiative in Saudi Arabia
}

\section{Yousef Ahmed Alomi* ${ }^{*}$, BSC. \\ Pharm, MSc. Clin Pharm, BCPS, BCNSP, DiBA, CDE, Critical Care Clinical Pharmacists, TPN \\ Clinical Pharmacist, Freelancer Business Planner, Content Editor and Data Analyst, Riyadh, Saudi Arabia. \\ Faiz Abdullah. Bahadig, R.Ph, Informatics Pharmacist, Pharmaceutical Care Department, King Abdul-Aziz Medical, City-WR-Jeddah, Ministry of National Guard, Saudi Arabia. \\ Hani Alhamdan, BSc.Pharm, MSc. Pharm, MBA, Director, Pharmaceutical Care services Department at KAMC-Jeddah, Ministry of National Guard, Saudi Arabia.}

\section{Correspondence:}

Dr. Yousef Ahmed Alomi, Bsc. Pharm, msc. Clin pharm, bcps, bCNSP, DiBA, CDE Critical Care Clinical Pharmacists, TPN Clinical Pharmacist, Freelancer Business Planner, Content Editor and Data Analyst, P.O.BOX 100, Riyadh 11392, Riyadh, SAUDI ARABIA.

Phone no: +966 504417712

E-mail:yalomi@gmail.com
Received: 22-10-2019;

Accepted: 01-01-2020

Copyright: (c) the author(s), publisher and licensee International Journal of Pharmacology and Clinical Sciences. This is an open-access article distributed under the terms of the Creative Commons Attribution Non-Commercial License, which permits unrestricted non-commercial use, distribution, and reproduction in any medium, provided the original work is properly cited.

This is an open access article distributed under the terms of the Creative Commons AttributionNonCommercial-ShareAlike 4.0 License

Access this article online

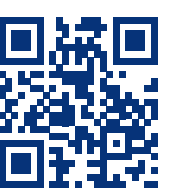

www.ijpcs.net

DOI:

10.5530/ijpcs.2020.9.21

\begin{abstract}
Objectives: To establish the pediatrics and neonates standardized concentration of central nervous system intravenous infusion as new initiatives in the Kingdom of Saudi Arabia. Methods: It is a new initiative project drove by national standardized concentration of central nervous system intravenous infusion services. The projects formulated from the international business model, pharmacy project guidelines and project management institution guidelines of a new project. The initiative project is written through project management professionals and consisted of several parts, including the initial phase, the planning phase, the execution phase, the monitoring and controlling phase. Results: The pediatrics and neonates standardized concentration of central nervous system intravenous infusion services with a defined vision, mission and goals. The services had multiple benefits including clinical and economic on patients, the continuous of the project confident by risk management model description and the monitoring and controlling of the services as explored in the review. The transition to operation project though closing project stage confirmed in the analysis. Conclusion: The pediatrics and neonates standardized concentration of central nervous system intravenous infusion services is new initiative as part of the intravenous admixture program. The pediatrics and neonates standardized concentration of central nervous system intravenous infusion properly reduce medication errors and improve patient safety culture system; it is highly recommended to implement in the Kingdom of Saudi Arabia.

Keywords: Pediatrics, Neonates, Standardized, Concentration, Central Nervous System,
\end{abstract} Intravenous, Services, Saudi Arabia.

\section{INTRODUCTION}

The national intravenous admixture program originated during the implementation of the pharmacy strategic plan 2012-2015. $\cdot^{[1,2]}$ It contained of multiple aspects, for an instant, guiltiness of aseptic technics, adult parenteral medications manual, design of intravenous admixture based on bed capacity, pediatrics parental medications manual and neonatal parental medications manual. ${ }^{[1]}$ All parenteral preparation guidelines had medications, stability after preparation and different concentration with various diluent solutions. In those manuals, the authors propose starting steps of standardized concentration of medications, including central nervous system medications. Several investigations showed that the unique concentration would prevent drug-related errors and decrease health care providers and pharmacist staff workload. ${ }^{[3-7]}$ The American Society of Health-System Pharmacists with other healthcare organizations underway and fortified to implement the standardized concentrations for safety. ${ }^{[8,9]}$ However, there are no local or Middle East studies to declare the pediatrics and neonates standardized concentration of central nervous system intravenous infusion. ${ }^{[10-16]}$ The aim of this project is to explore the pediatrics and neonates standardized concentration of Central
Nervous System (CNS) intravenous infusion as new initiatives in the Kingdom of Saudi Arabia.

\section{Project Management Professional \\ Method of the Project}

It is a new initiative project drove from the national IV admixture and chemotherapy program. ${ }^{[1]}$ The task force team of standardized intravenous pediatrics and neonates central nervous system medication concentration formulated and contained the author's expert in the parenteral medications. The committee utilized and drove the pharmacy parenteral administration guidelines, from the textbook and international literature of the intravenous pediatrics and neonates central nervous system medication concentration written by utilizing the international business model, pharmacy project guidelines and project management institution guidelines of a new project. ${ }^{[17-20]}$ The standardized concentration adjusted based on the acceptable concentration, daily dose and the volume of bag as possible. The project is written through project management professionals and comprised of several parts, including the initial phase, the planning phase, the execution phase, the monitoring and controlling phase. 


\section{Initiative Phase}

\section{Assessment Needs}

The majority of the intravenous admixture services prepare multiple medications with various concentrations and different diluent solutions daily. The nurses administer multiple medications with various concentration and solution daily. There was a high workload of pharmacy staff through parenteral admixture services and received by patients through nursing care. The large workload of various concentrations and the different solutions may lead to preparation or administration errors. In progress, the standardized concentration and solution were required to prevent mistakes by reducing the workload of pharmacy and other healthcare professionals. Also, there was an opportunity to inspire the manufactures to produce the same time the standardized concentration and ready-made solutions

\section{SWOT Analysis}

There are common and popular analysis tools by name the SWOT Analysis stands for strengths, weaknesses and opportunities and threats points. The strengths points of the project are medication mistake prevention, reducing the healthcare professionals and pharmacy staff workload, while the weak points are a limited number of diluent solutions and medication concentration. In addition, the opportunity points are the presence of quality patient safety programs and the process of the local and international accreditation. Moreover, the threat points are the non-availability of a healthcare leader and the non-implementation of the pharmacy strategic plan.

\section{Market Analysis}

Multiple medications came as ampoules solution or powers for reconstitution. Some pharmaceutical companies yield the medications ready-made a solution or diluted with the solution ready for administration. The ready-made of medications was the same as the strength of medications regardless of the concentration suitable or not for administration through a central venous or peripheral line. Moreover, the pharmaceutical care services had guidelines for the preparation of intravenous medications with different concentrations and diluted solutions. Several above factors may surge workload and subsequent, leading to medication errors. The standardized concentration of parenteral medications properly reduces the workload and implement the safety of the medication in practice.
Planning Phase

\section{Scope of the Project}

The project covers the pediatrics and neonates standardized concentration of central nervous system intravenous infusion based on the common dosing and frequency administration including a suitable diluent solution.

\section{Vision, Missions, Goals}

The vision of the project to reach best with high-quality pediatrics and neonates standardized concentration of central nervous system intravenous infusion, while the message is to provide the high quality stable intravenous standardized concentration of central nervous system medications with suitable dosing and frequency administration. The goals of this project is to standardized the concentration of intravenous central nervous system medications, to prevent medication errors related to concentration, to decrease the workload of pharmacy and medical staff, to prevent intravenous central nervous system medications wastage and economic burden on the healthcare system.

\section{Project Description}

The following policies were put in place for every pharmacist and other health care individuals: ${ }^{[21,22]}$

$\checkmark$ The pediatrics and neonates standardized concentration of central nervous system intravenous infusion committee should be formulated at healthcare organizations.

$\checkmark$ The pediatrics and neonates standardized concentration of central nervous system intravenous infusion committee should consist of pediatrics IV pharmacist and pharmacy technician, pediatrics physician and nurse representative, neonatal physician and nurse representative.

$\checkmark$ The committee revises the pediatrics and neonates standardized concentration of central nervous system intravenous infusion and updates at least every year.

$\checkmark$ The pediatrics and neonates standardized concentration of central nervous system intravenous infusion education and training sessions should be conducted by the committee to all healthcare providers, including physicians and nurses, with pharmacy staff.

$\checkmark$ The pediatrics and neonates standardized concentration of central nervous system intravenous infusion distributed to healthcare sectors at the institutions (Table 1).

$\checkmark$ The physician writes the prescription based on the pediatrics and neonates standardized concentration of central nervous system intravenous infusion.

$\checkmark$ If the physician wishes to prescribe outside the pediatrics and neonates standardized concentration of central nervous system intravenous infusion guidelines, he should document the justification.

$\checkmark$ The prescription should send to the pharmacy and pediatrics IV pharmacist and pharmacy technician will prepare it based on the pediatrics and neonates standardized concentration of central nervous system intravenous infusion.

$\checkmark$ The pharmacy staff should send the medications to the nursing department and the nurse administers the medications based on the pediatrics and neonates standardized concentration of central nervous system intravenous infusion guidelines.The pharmacy department should measure the clinical outcome of the pediatrics and neonates standardized concentration of central nervous system intravenous infusion.

$\checkmark$ The pharmacy department should measure the economic outcome of the pediatrics and neonates standardized concentration of central nervous system intravenous infusion.

$\checkmark$ The pharmacy department should document any prescription non-adherence to the pediatrics and neonates standardized concentration of central nervous system intravenous infusion.

\section{Plan Cost Management}

The fiscal budget must be set in each new project. The cost enclosed the education courses, the administration team meeting and updated references. The budget must be observed from time to time.

\section{Executing Phase Management Team}

Oneofthetools of the professional's management project skills were the leading project by the team. The team contained of several essential members, including neurology pediatrics clinical pharmacist, parenteral medications preparation pharmacist, pharmacy technician, pharmacy total quality management, pediatrics medications safety pharmacist and pediatrics neuroscience physician. The team should implement and follow the project. The team had to have education and training for medical and pharmacy staff on the project and updating of medications concentration regularly based on evidence-based literature. 
I:

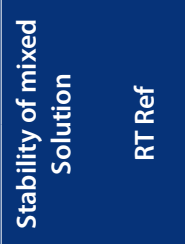

III

.

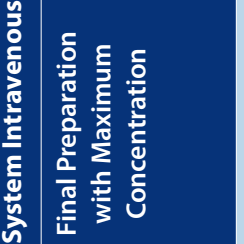

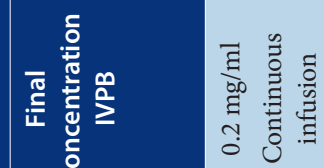

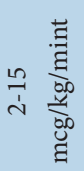

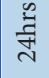

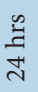

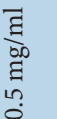

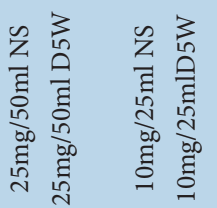

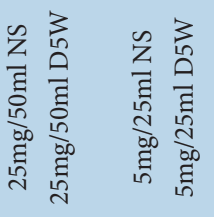

$\overleftrightarrow{z}$

$\sum_{0}^{3}$

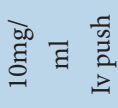

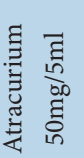

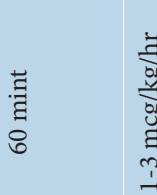

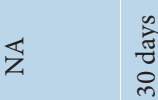

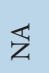

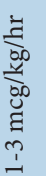

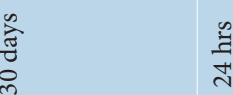

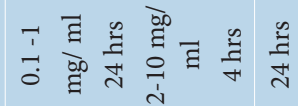

艺

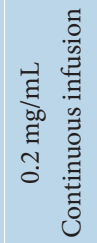

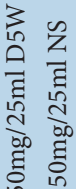

茫瓷

ํㅣㄹ

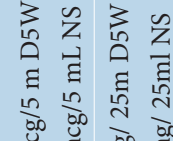

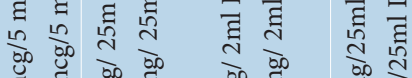

范范总

㤩

$\bar{\Xi}$
है
!n

छี

瓷

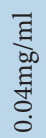

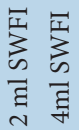

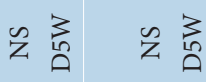

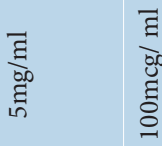

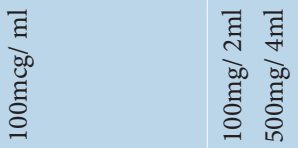

르

虫乏

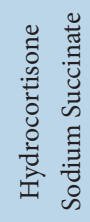

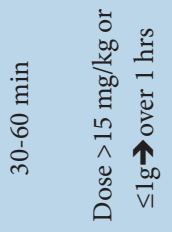

$\underset{\substack{\xi \\ \hdashline}}{q}$

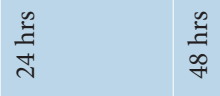

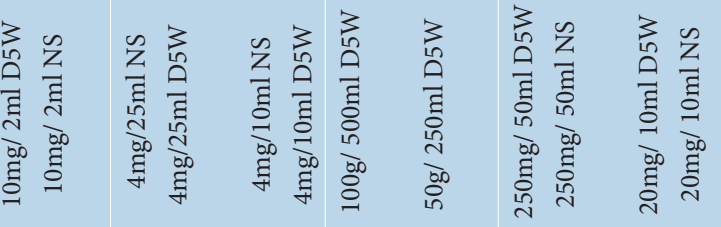

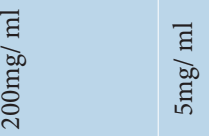

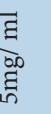




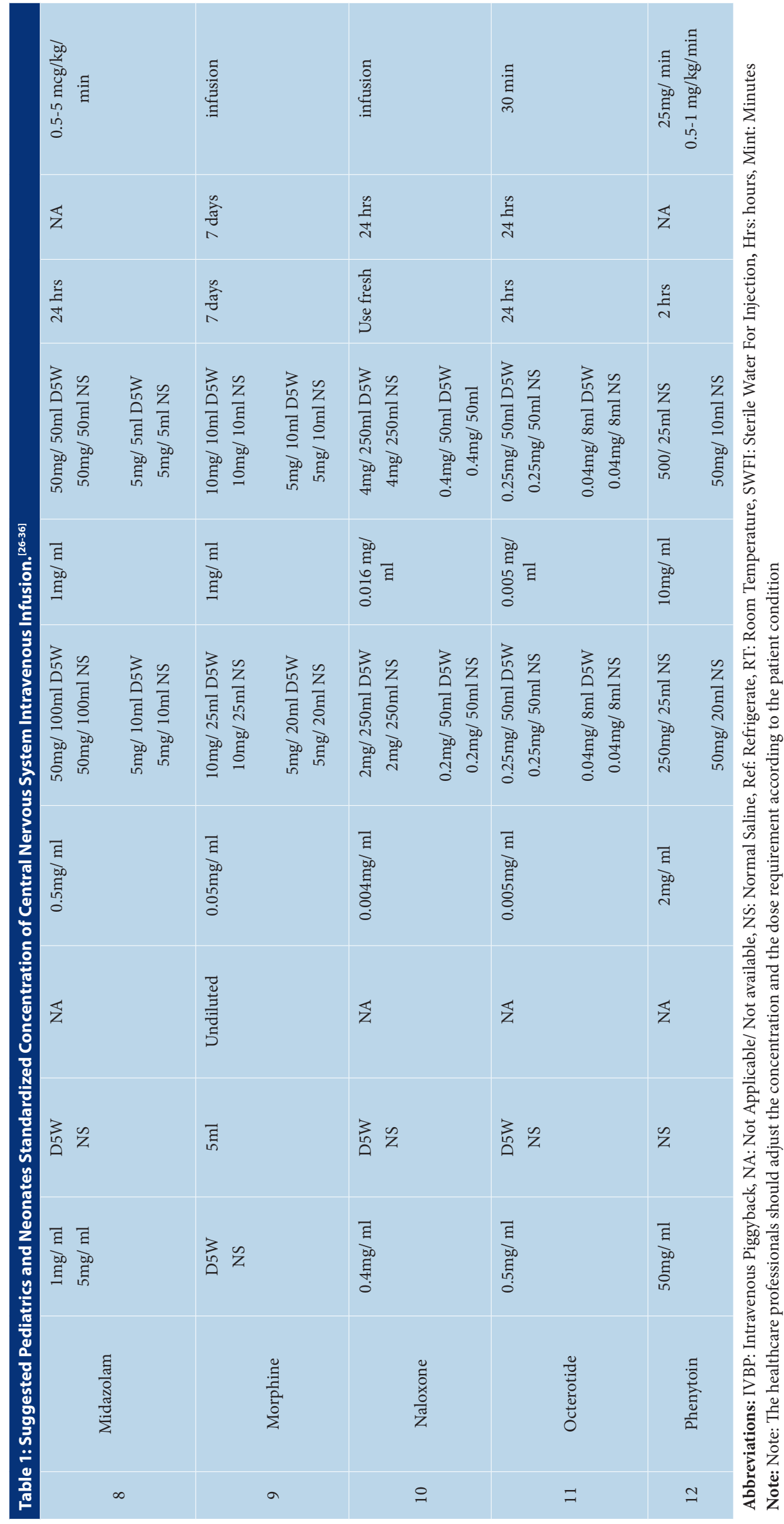

\section{Education and Training}

Foe any new project, there are several pediatrics and neonates standardized concentration of central nervous system intravenous infusion educational sessions and training courses should be conducted for pharmacy staff, including pharmacists and pharmacy technicians. Other courses should be carried to healthcare providers, including physicians and nurses. Moreover, the management team members should obtain the educational courses about the project and any newly joint pharmacy or healthcare provider's staff should the orientation sessions with the involvement of the new project.

\section{Monitoring and Controlling Phase Project Total Quality Management}

Several methods used to measure the total quality management of the new project. The Balance Scored Card one the famous new system in practice. ${ }^{[23]}$ The BSC contained four types of measurement tools. There are many tools used for total quantity management including customer, finance, internal process, education and innovation. The international process part might use the assessment of healthcare services of pediatrics and neonatal standardized concentration of central nervous system medications. The second type related to the education and competency of healthcare professionals, including pharmacy staff, which involved the clinical outcome of pediatrics and neonatal standardized concentration of central nervous system medications. The third type, which measures the financial-related issues, for instance, the type had another example of measuring the economicimpact of thepediatrics and neonates standardized concentration of central nervous system intravenous infusion. The other type was the customer types with measuring the patient's satisfaction, healthcare providers and pharmacy staff of pediatrics and neonatal standardized concentration of central nervous system medications satisfaction in the Kingdom of Saudi Arabia.

\section{Risk Management}

The budget risks, scope risks, schedule risks, personal risks, technical risks and quality risks are types of risk management. ${ }^{[24,25]}$ The majority of risks exposed to the current project were personnel, budget, technical and quality risks. The project might suffer from personal risks that are including a shortage of pharmacists and pharmacy technicians or trained them. The budget types are another example of common risks that involve not enough budget for education and training for pharmacy and healthcare professionals 
or electronic update references. Also, the technical risk might be exposed, which involves a non-friendly used computer system within computerized physician order entry (CPOE) or non-available altering services inside the electronic prescribing. The quality risks are another risk that might be exposed to the new project including related non-standardized medications safety procedures and not sufficient quality management pharmacy staff.

\section{Closing of the Project}

The pediatrics and neonates standardized concentration of central nervous system intravenous infusion at all healthcare governmental and private organizations sectors is a request to prevent drug-related problems that might lead to admission to critical care or death prevent an unnecessary economic burden on healthcare services in the Kingdom of Saudi Arabia. The project should endure intravenous parenteral medications in each pharmacy's services with the involvement of related committees. The pediatrics and neonatal CNS medication with standardized concentration Education and training should be done periodically. Update CNS medications concentration with more expanded of new parental CNS medications for adults is demand in the future. The pharmacy staff in the IV admixture services should make annual celebration for them is highly recommended in the Kingdom of Saudi Arabia.

\section{ACKNOWLEDGEMENT}

None.

\section{CONFLICT OF INTEREST}

None.

\section{FUNDING}

None

\section{CONSENT FOR PUBLICATIONS}

Informed consent was obtained from all the participants

\section{ETHICAL APPROVAL}

This research exempted from research and ethical committee or an institutional review board (IRB) approval.

https://www.hhs.gov/ohrp/regulations-andpolicy/decision-charts-2018/index.html

\section{ABBREVIATIONS}

MOH: Ministry of Health; KSA: Kingdom of Saudi Arabia; ASHP: American Society of Health-System Pharmacists; ISMP: Institution of Safe Medication Practice; SWOT: Strengths, Weaknesses, Opportunities and Threats; CNS: Central Nervous System; IV: Intravenous; BSC: Balance Scored Cards; IAC: intravenous admixture committee.

\section{ORCID ID}

Yousef Ahmed Alomi org/0000-0003-1381-628X

https://orcid.

\section{REFERENCES}

1. Alomi YA. National Intravenous (IV) Therapy Program at $\mathrm{MOH}$ in Saudi Arabia. EC Pharm Sci. 2016;3(2.3):307-11.

2. AlomiYA, Alghamdi SJ, Alattyh RA. Strategic plan of general administration of pharmaceutical care at ministry of health in Saudi Arabia 2012-2022. J Pharm Pharm Scien. 2015;1(13):1-8.

3. Bullock J, Jordan D, Gawlinski A, et al. Standardizing IV infusion medication concentrations to reduce variability in medication errors. Critical Care Nursing Clinics of North America. 2006;18(4):51521

4. Jung B, Couldry R, Wilkinson S, et al. Implementation of standardized dosing units for i.v. medications. Am J Heal Pharm. 2014;71(24):2153-8.

5. Larsen GY. Standard drug concentrations and smart-pump technology reduce continuous-medication-infusion errors in pediatric patients. Pediatrics. 2005;116(1):e21-5.

6. Hilmas E, Sowan A, Gaffoor M, et al. Implementation and evaluation of a comprehensive system to deliver pediatric continuous infusion medications with standardized concentrations. Am J Heal Pharm. 2010;67(1):58-69

7. Murray KL, Wright D, Laxton B, et al. Implementation of standardized pediatric i.v. medication concentrations. Am J Heal Pharm. 2014;71(17):15008.

8. American Society of Health-System Pharmacists. Standardized Concentrations: Adult Continuous IV Infusions Version 1.01. 2016. Available from https:// www.ashp.org/-/media/assets/pharmacy-practice/s4s/docs/s4s-iv-adult-continuous-infusionguiding-principles.ashx.

9. Institute for Safe Medication Practices (ISMP). Standard Concentrations of Neonatal Drug Infusions. ISMP. 2011.

10. Irwin D, Vaillancourt R, Dalgleish D, et al. Standard concentrations of high-alert drug infusions across paediatric acute care. Paediatr Child Health. 2008;13(5):371-6.

11. Phillips MS. Standardizing i.v. infusion concentrations: National survey results. Am J Heal Pharm. $2011 ; 68(22): 2176-82$.

12. Walroth TA, Dossett HA, Doolin M, et al. Standardizing concentrations of adult drug infusions in Indiana. Am J Heal Pharm. 2017;74(7):491-7.

13. Perkins J, Aguado-Lorenzo V, Arenas-Lopez S. Standard concentration infusions in paediatric intensive care: The clinical approach. J Pharm Pharmacol. 2017;69(5):537-43.

14. Arenas-López S, Stanley IM, Tunstell P, et al. Safe implementation of standard concentration infusions in paediatric intensive care. J Pharm Pharmacol. 2017;69(5):529-36.

15. Oskarsdottir T, Harris D, Sutherland $A$, et al. A national scoping survey of standard infusions in paediatric and neonatal intensive care units in the United Kingdom. J Pharm Pharmacol. 2018;70(10):1324-31.

16. Irwin D, Vaillancourt R, Dalgleish D, et al. Standard concentrations of high-alert drug infusions across paediatric acute care. Paediatr Child Health.
2008;13(5):371-6

17. McDonough R. Writing a business plan for a new pharmacy service. The Dynamics of Pharmaceutical Care: Enriching Patients' Health. 2010;23:1-2.

18. Harris IM, Baker E, Berry TM, et al. Developing a business-practice model for pharmacy services in ambulatory settings. Pharmacotherapy. 2008;28(2):7e-34e

19. Sachdev G. Sustainable business models: Systematic approach toward successful ambulatory care pharmacy practice. Am J Heal Pharm. 2014;71(16):1366-74.

20. PMBOK Guide. A Guide to the Project Management Body of Knowledge. Sixth Edit. Project Management Institute, Inc. 2017;2-111.

21. Mitchell A, Sommo P, Mocerine T, et al. A standardized approach to pediatric parenteral medication delivery. Hospital Pharmacy. 2004;39(5):43359.

22. Sowan AK, Vaidya VU, Soeken KL, et al. Computerized orders with standardized concentrations decrease dispensing errors of continuous infusion medications for pediatrics. J Pediatr Pharmacol Ther. 2010;15(3):189-202.

23. Kaplan RS, Norton DP. The balanced scorecard: Measures that drive performance. Harvard Business Review. 2005;83(7):172. Cited 2020 Mar 15. Available from: https://hbr.org/1992/01/thebalanced-scorecard-measures-that-drive-performance-2.

24. Ray S. The Risk Management Process in Project Management. Project Manager. 2017. Cited 2020 Mar 15. Available from: https://www.projectmanager.com/blog/risk-management-process-steps.

25. Kaplan RS, Mikes A. Managing risks: A new framework. Harvard Business Review. 2012;90(6):4860. Cited 2020 Mar 15. Available from: https://hbr. org/2012/06/managing-risks-a-new-framework.

26. Ministry of Health. Ministry of Health Formulary. Health Ministry of Health. 2012.

27. Saudi Food and Drug Authority. List of human medicine and herbal health. 2019. [cited 2019 Jun 17]. Available from: https://www.sfda.gov.sa/en/ drug/resources/Pages/DrugsUnderRegistrations. aspx

28. Baxter K, Aikman K, Luckhurst R, et al. British National Formulary 78 (BNF). Royal Phamaceutical Society. 2019;1-1701.

29. Alomi YA, et al. Pediatrics Parenteral Dilution Manual. Ministry of Health. 2015. Available from: https://www.researchgate.net/publication/281710402_Pediatrics_Parenteral_Dilution_ Manual

30. Alomi YA, et al. Neonates Parenteral Dilution Manual. Ministry of Health. 2015. Available from: https://www.researchgate.net/publication/281710411_Neonates_Parenteral_Dilution_ Manual

31. Wolters Kluwer Clinical Drug Information. Inc. (Lexi-Drugs). Wolters Kluwer Clinical Drug Information, Inc. 2020.

32. Drugs.com. Drugs.com, Prescription Drug Information, Interactions and Side Effects. Drugs.com. 2020. [cited 2020 Jun 16]. Available from: https:// www.drugs.com/

33. King Abdulaziz Medical City. Unified IV Manual. 2020.

34. Wolters Kluwer Clinical Drug Information. Inc. (ASHF Essentials adults and pediatrics). Wolters Kluwer Clinical Drug Information, Inc. 2020.

35. Wolters Kluwer Clinical Drug Information. Inc. (Pediatrics and Neonatal Lexi-Drugs). Wolters Kluwer Clinical Drug Information, Inc. 2020.

36. Wolters Kluwer Clinical Drug Information. Inc. (Nursing Lexi-Drug). Wolters Kluwer Clinical Drug Information, Inc. 2020. 